\title{
A systematic critical review on MRI in spondyloarthritis
}

Bodil Arnbak ${ }^{1,2^{*}}$, Charlotte Leboeuf-Yde ${ }^{1,2}$ and Tue Secher Jensen ${ }^{1,2}$

\begin{abstract}
Introduction: Magnetic resonance imaging (MRI) has been proven capable of showing inflammatory and structural changes in patients with spondyloarthritis (SpA) and has become widely used in the diagnosis of SpA. Despite this, no systematic reviews evaluate the diagnostic utility of MRI for SpA. Therefore, the objective of this systematic review was to determine the evidence for the utility of MRI in the clinical diagnosis of SpA. The aims were to identify which MRI findings are associated with the diagnosis of SpA and to quantify this association.

Methods: MEDLINE and EMBASE were electronically searched. Inclusion criteria were cross-sectional or longitudinal case-control or cohort MRI studies. The studies required a group with either SpA or inflammatory back pain (IBP) and a non-case group without SpA or IBP. Each group required a minimum of 20 participants. The included articles had to report results containing raw numbers suitable for the construction of two-by-two tables or report results by sensitivity and specificity for cross-sectional studies or odds ratios, relative risk ratios, or likelihood ratios for longitudinal studies. Method quality was assessed by using criteria based on the QUADAS tool.

Results: In total, 2,395 articles were identified in MEDLINE and EMBASE before November 2011. All articles were reviewed by title and abstract. Seventy-seven articles were reviewed by full text, and 10 met the inclusion criteria. Two were considered of high quality: one evaluated the sacroiliac joints, and the other, the spine. Because of the small number of high-quality studies, a meta-analysis was not performed. The two high-quality studies found a positive association between MRI findings (bone marrow edema, erosions, fat infiltrations, global assessment of sacroiliitis, and ankylosis) and the diagnosis of IBP and SpA.

Conclusion: In this review, several MRI findings were found to be associated with SpA. However, because of the small number of high-quality studies, the evidence for the utility of MRI in the diagnosis of SpA must be considered limited. Therefore, caution should be taken to ensure that inflammatory and structural MRI findings are not interpreted as being more specific for SpA than is supported by research.
\end{abstract}

\section{Introduction}

Spondyloarthritis $(\mathrm{SpA})$ is a rheumatologic disease that comprises the different disease entities of ankylosing spondylitis (AS), reactive arthritis, psoriasis arthritis, spondyloarthritis associated with inflammatory bowel disease, and undifferentiated spondyloarthritis. The main symptoms are chronic back pain, associated with extraspinal manifestations and particular laboratory findings. It usually emerges in the second or third decade of life and, although it is relatively rare, the prevalence

\footnotetext{
* Correspondence: Bodil.Arnbak@SLB.Regionsyddanmark.dk ${ }^{1}$ Research Department, Spine Centre of Southern Denmark, Hospital Lillebaelt, Clinical Locomotion Network, Oestre Hougvej 55, Middelfart 5500, Denmark

Full list of author information is available at the end of the article
}

being about $0.25 \%$ to $1 \%$ in the European population [1], it is a health condition worthy of attention because it can be debilitating for those affected, especially if undiagnosed.

With the introduction of tumor necrosis factor- $\alpha$ inhibitors in the treatment of preradiographic SpA $[2,3]$, the interest in early and precise diagnosis has increased. However, the early diagnosis of SpA is often difficult. In chronic back pain patients, the most common diagnosis is nonspecific low-back pain (NSLBP), and SpA is estimated to contribute only $5 \%$ of the causes of back pain in primary care patients [4]. Even though plain radiography can detect structural changes of the spine and sacroiliac joints (SIJs), patients often have symptoms for several years before these changes become evident [5].

\section{Biomed Central}

(c) 2012 Arnbak et al.; licensee BioMed Central Ltd. This is an open access article distributed under the terms of the Creative Commons Attribution License (http://creativecommons.org/licenses/by/2.0), which permits unrestricted use, distribution, and reproduction in any medium, provided the original work is properly cited. 
Over the past three decades, magnetic resonance imaging (MRI) has proven capable of detecting preradiographic inflammatory lesions seen in SpA patients [6,7], and optimism exists regarding the opportunities MRI can offer for early diagnosis of SpA. This is indicated by the inclusion of MRI of the SIJ in the criteria for axial SpA developed by the Assessment of SpondyloArthritis international Society (ASAS) in 2009 [8]. However, to our knowledge, no systematic critical literature reviews have addressed the utility of MRI in the diagnosis of SpA.

The objective of this systematic critical review was therefore to determine the level of evidence for the utility of MRI in relation to the clinical diagnosis of SpA. The specific aims of this review were to identify which MRI findings are associated with the diagnosis of SpA and to quantify this association.

\section{Methods}

Search method for identification of studies

Searches were made in the MEDLINE and EMBASE databases for articles published before November 2011. The following search terms were used as free text and $\mathrm{MeSH}$ terms: "magnetic resonance imaging," "spondyloarthritis," "ankylosing spondylitis," "sacroiliitis," "psoriasis arthritis," "reactive arthritis," "arthritis and inflammatory bowel disease," and "inflammatory back pain." Different forms of spelling and synonyms for each term were also used.

\section{Inclusion criteria for considering studies for this review Types of studies}

Prospective and retrospective case-control or cohort studies were accepted. Both cross-sectional and longitudinal studies were accepted. Articles in English, German, French, Norwegian, Swedish, and Danish were included, as these were the linguistic capabilities of the author team.

\section{Study subjects}

Studies were required to include a group of cases with the clinical diagnosis of SpA or inflammatory back pain (IBP) and a group of noncases without SpA or IBP, respectively. Each case and noncase group had to contain more than 20 participants. The criteria for sample size were set arbitrarily to reduce the risk of imprecise estimates with very wide confidence intervals (CIs). The mean age of the study sample had to be older than 18 and younger than 65 years.

\section{Index test}

The index test under evaluation was MRI of the axial skeleton. The field strength had to be a minimum of 1.5 Tesla to secure a minimal standard of the imaging. No other limitations were set for the technical equipment used, and all types of MRI sequences were accepted.

\section{Target condition}

The target condition was either SpA, one of the disease subgroups of SpA (AS, psoriasis arthritis, reactive arthritis, arthritis associated with IBP, or undifferentiated SpA) or IBP.

\section{Reference standard}

The reference standard was the clinical diagnosis of one of the target conditions defined by a diagnostic criterion or by expert opinion. The diagnosis had to have been made from clinical information. Information from plain radiography and serologic testing was accepted as part of the diagnosis.

\section{Results presentation}

Articles were included only if they reported one of the following: Results containing raw numbers suitable for the construction of two-by-two tables, for cross-sectional studies if they reported results by sensitivity and specificity, and for longitudinal studies if they reported odds ratios, relative risk ratios, or likelihood ratios.

\section{Data collection and analysis Selection of studies}

Initially, the first author reviewed the titles and abstracts of the search results for identification of relevant articles to be retrieved in full text. The full texts were screened for relevance, and double publications were excluded this stage. Subsequently, the identified articles were reviewed in full text for data extraction by the first and third authors.

\section{Data extraction and management}

The first and third authors independently extracted the data from the relevant articles according to a check-list specifying the information needed regarding the following factors: (a) study sample(s), (b) clinical diagnosis, (c) MRI findings, (d) MRI technique, (e) MRI evaluation, (f) data analysis, and (g) results. In case of disagreements, consensus was reached through discussion.

\section{Assessment of methodologic quality}

The quality of the included articles was assessed with a set of quality criteria, based on the QUADAS tool [9]. The quality assessment was subdivided into four topics: (a) study sampling, (b) clinical diagnosis, (c) MRI evaluation, and (d) data analysis and results. Each item was rated from 0 to 2 , resulting in a maximum of 8 points per article (Table 1). For longitudinal studies, the reporting on drop-out rates and reasons for dropping out were to be assessed.

The assessment was performed independently by the first and the third authors. Any disagreements in the assessments were settled by consensus and discussion with the second author. Articles with a quality score of more than 5 points were arbitrarily regarded as high-quality studies. Only results from high-quality studies were further reviewed.

\section{Statistical analysis and data synthesis}

Sensitivity and specificity were retrieved from the article where possible and calculated from raw data when not 
Table 1 Quality scores for the articles on MRI and SpA fulfilling the inclusion criteria

\begin{tabular}{|c|c|c|c|c|c|c|c|c|c|}
\hline & $\begin{array}{l}\text { Bollow } \\
\text { et al. } \\
\text { (1995) [10] }\end{array}$ & $\begin{array}{l}\text { Klauser } \\
\text { et al. } \\
\text { (2004) [11] }\end{array}$ & $\begin{array}{l}\text { Brandt } \\
\text { et al. } \\
\text { (2007) [12] }\end{array}$ & $\begin{array}{l}\text { Weber } \\
\text { et al. } \\
\text { (2010) [13] }\end{array}$ & $\begin{array}{l}\text { Wick et al. } \\
(2010) \\
{[14]}\end{array}$ & $\begin{array}{l}\text { Kim et al. } \\
(2008) \\
{[15]}\end{array}$ & $\begin{array}{l}\text { Weber } \\
\text { et al. } \\
\text { (2009) [16] }\end{array}$ & $\begin{array}{l}\text { Bennett } \\
\text { et al. (2009) } \\
\text { [17] }\end{array}$ & $\begin{array}{l}\text { Bennett } \\
\text { et al. (2009) } \\
\text { [18] }\end{array}$ \\
\hline Study sampling (0-1) & 1 & 0 & 1 & 2 & 1 & 1 & 2 & 1 & 1 \\
\hline Diagnosis $(0-1)$ & 1 & 0 & 0 & 1 & 0 & 1 & 1 & 0 & 0 \\
\hline MRI evaluation (0-1) & 0 & 0 & 0 & 2 & 2 & 1 & 2 & 2 & 1 \\
\hline $\begin{array}{l}\text { Data analysis and } \\
\text { presentation of } \\
\text { results }(0-1)\end{array}$ & 0 & 1 & 1 & 2 & 0 & 1 & 2 & 1 & 1 \\
\hline Total (0-8) & 2 & 1 & 2 & 7 & 3 & 4 & 7 & 4 & 3 \\
\hline
\end{tabular}

Diagnosis assessed on IBP or SpA diagnosed by criteria (best) or expert opinion (second best), same diagnosis performed on whole sample, diagnosis independent of MRI, diagnosis blinded for MRI, and reproducibility of diagnosis tested (inter- and intraexaminer reliability tested and reported). MRI evaluation assessed on clear definition of each relevant MRI finding, MRI blinded from diagnosis, reproducibility (inter- and intraexaminer reliability tested and reported), and short time between the MRI scan and diagnosis. Data analysis and presentation of results assessed on statistical significance test and confidence intervals reported where relevant and results presented in an understandable way. 0, Nonacceptable; 1, Reasonable; 2, Good; SpA, spondyloarthritis; IBP, inflammatory back pain.

reported in the article. The Wilson score method without continuity correction was used to calculate the $95 \%$ $\mathrm{CI}$, if it were not reported in the article. Meta-analysis was planned to be performed on homogeneous highquality studies, but was not performed because of insufficient data.

\section{Results}

\section{Description of studies}

In all, 1,336 articles were found in MEDLINE, and 2,359, in EMBASE. After elimination of duplicates, 2,395 articles were reviewed by title and abstract, and 76 articles were identified for assessment in full text. After full-text review, nine cross-sectional articles met the inclusion criteria [10-18] (Figure 1). No longitudinal studies met the inclusion criteria. Reasons for exclusion of articles reviewed in full text are presented in Table 2 for articles on cross-sectional studies and in Table 3 for articles on longitudinal studies.

\section{Description of included articles}

The nine articles meeting the inclusion criteria were based on eight study samples and were published between 1995 and 2010 [10-18]. Two studies were conducted on the same study population $[17,18]$. Seven of the nine articles were designed to address the diagnostic utility of MRI in the diagnosis of either AS, SpA, or IBP. One article compared ultrasound with MRI in the diagnosis of IBP [11], and one article evaluated referral recommendations [12]. Five studies reported results for the SIJ [10-14], and four, the results for the spine; one of the lumbar spine [15] and three of the whole spine [16-18]. The sample sizes varied from 85 to 187 participants. The diagnoses under evaluation were AS [10,12-16], SpA $[10,12,14,17,18]$, and IBP $[11,13,16]$. The groups of noncases were no LBP [11,13,16-18] and/or noninflammatory low-back pain, such as NSLBP, degenerative arthritis, cancer, and LBP of

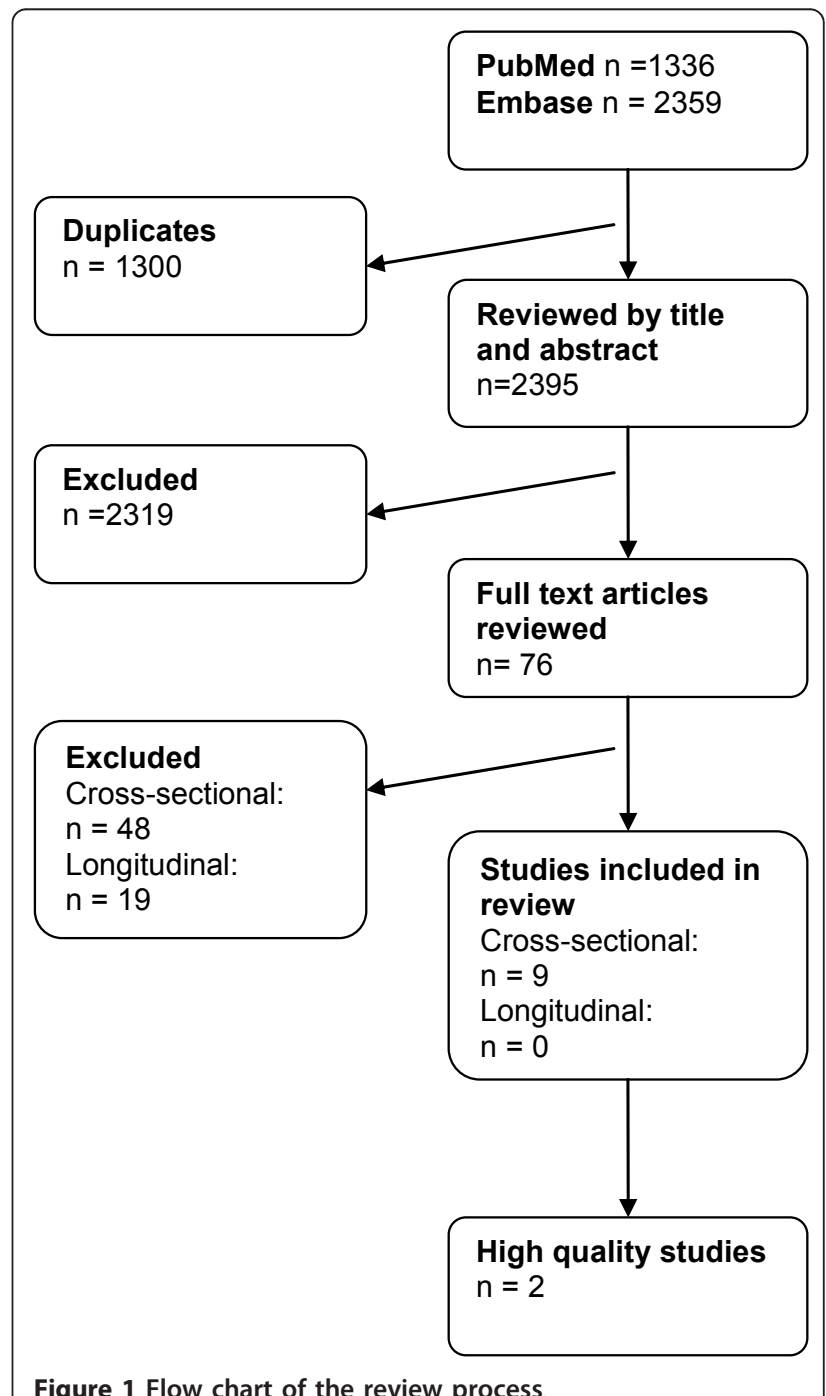

Figure 1 Flow chart of the review process 
Table 2 Reasons for excluding retrieved articles on cross-sectional studies

\begin{tabular}{|c|c|}
\hline Study & Reasons for exclusion \\
\hline Ahlstrom H, et al. (1990) [6] & $<20$ controls \\
\hline Algin O, et al. (2009) [25] & $<20$ controls \\
\hline Algin O, et al. (2010) [26] & $<20$ controls \\
\hline Baraliakos X, et al. (2005) [27] & No controls \\
\hline Bejia I, et al. (2004) [28] & $<20$ cases \\
\hline Blum U, et al. (1996) [29] & Field strength, $<1.5$ Tesla \\
\hline Bochkova AG, et al. (2010) [30] & No controls \\
\hline Bollow $M$, et al. (1993) [31] & Double publication on Bollow et al. [10] \\
\hline Bollow M, et al. (1994) [32] & Double publication on Bollow et al. [10] \\
\hline Bozgeyik Z, et al. (2008) [33] & No controls \\
\hline Braun J, et al. (1994) [34] & $<20$ controls \\
\hline Braun J, et al. (1998) [35] & Reference standard (HLA-B27 status) not a clinical diagnosis \\
\hline Bredella MA, et al. (2006) [36] & No controls \\
\hline Chung H Y, et al. (2011) [37] & No controls \\
\hline Docherty P, et al. (1992) [38] & $<20$ controls \\
\hline Friedburg H, et al. (1987) [39] & No controls \\
\hline Gleeson TG, et al. (2005) [40] & $<20$ cases \\
\hline Gupta AD, et al. (2009) [41] & $<20$ controls \\
\hline Hanly JGJ, et al. (1994) [42] & $<20$ controls \\
\hline Heuft-Dorenbosch L, et al. (2006) [43] & Reference standard (plain radiographic) not a clinical diagnosis \\
\hline Heuft-Dorenbosch L, et al. (2006) [44] & No controls \\
\hline Heuft-Dorenbosch L, et al. (2007) [45] & No controls \\
\hline Inanc N, et al. (2005) [46] & Reference standard (plain radiographic) not a clinical diagnosis \\
\hline Jevtic V, et al. (1996) [47] & No controls \\
\hline Liao Z, et al. (2009) [48] & No MRI of the control group \\
\hline Liao Z, et al. (2011) [49] & No controls \\
\hline Luukkainen RK, et al. (2007) [50] & No controls \\
\hline Marc V, et al. (1997) [51] & $<20$ controls \\
\hline McNally EG, et al. (2001) [52] & $<20$ cases \\
\hline Muche B, et al. (2003) [53] & No controls \\
\hline Murphey MD, et al. (1991) [54] & $<20$ controls \\
\hline Orchard TR, et al. (2009) [55] & $<20$ cases \\
\hline Peterova V et al. (2006) [56] & No controls \\
\hline Puhakka KB, et al. (2003) [57] & No controls \\
\hline Remy, et al. (1996) [58] & No controls \\
\hline Rennie WJ, et al. (2009) [59] & $<20$ controls \\
\hline Rudwaleit M, et al. (2009) [60] & $<20$ controls \\
\hline Rudwaleit M, et al. (2009) [8] & Insufficient result presentation \\
\hline Rudwaleit M, et al. (2009) [61] & Insufficient result presentation \\
\hline Sreedhar C, et al. (2006) [62] & $<20$ cases \\
\hline Weber U, et al. (2007) [63] & $<20$ controls \\
\hline Weber U, et al. (2010) [64] & Double publication on Weber et al. [13] \\
\hline Wecbach et al. (2009) [65] & No controls \\
\hline Wienands K, et al. (1990) [66] & No controls \\
\hline Williamson L, et al. (2004) [67] & Reference standard (orthopedic test) not a clinical diagnosis \\
\hline Wittram C, et al. (1996) [68] & $<20$ controls \\
\hline Wittram C, et al. (1996) [69] & $<20$ controls \\
\hline Yu W, et al. (1998) [70] & $<20$ controls \\
\hline
\end{tabular}

Studies may have met exclusion criteria other than those listed in the table. MRI, magnetic resonance imaging. 
Table 3 Reasons for excluding retrieved articles on longitudinal studies

\begin{tabular}{ll}
\hline Study & Reasons for exclusion \\
\hline Althoff CE, et al. (2009) [71] & Insufficient result presentation \\
Aydin SZ, et al (2011) [72] & $<20$ controls \\
Baraliakos X, et al. (2008) [73] & No controls \\
Battafarano DF, et al. (1993) [74] & $<20$ controls \\
Bennett AN, et al. (2008) [7] & No controls \\
Bigot J, et al. (1999) [75] & $<20$ control \\
Brandt J, et al. (1999) [76] & No controls \\
Chiowchanwisawakit P, et al. (2011) [77] & No controls \\
Dougados M, et al. (2001) [78] & Insufficient result presentation \\
Hermann J, et al. (2009) [79] & Insufficient result presentation \\
Madsen K, et al. (2010) [80] & No controls \\
Macsymowych WP, et al. (2010) [81] & No controls \\
Marzo-Ortega H, et al. (2008) [82] & $<20$ in each control group \\
Oostveen J, et al. (1999) [83] & No controls \\
Pedersen SJ, et al. (2011) [84] & No controls \\
Puhakka KB, et al. (2004) [85] & No controls \\
Remplik P, et al. (2005) [86] & $<20$ cases \\
Shankar S, et al. (2009) [87] & Insufficient result presentation \\
Song IH, et al. (2011) [88] & No controls \\
\hline
\end{tabular}

Studies may have met exclusion criteria other than those listed in the table.

unknown origin $[10,12-15,17,18]$. For further details of the included studies, see Table 4.

All studies used an MRI scanner with a field strength of 1.5 Tesla. Four of the included articles had no description of the field strength, and the corresponding authors were therefore contacted for information of the field strength. Eight of the nine articles reported which MRI protocol was used [10,11,13-18]. For the SIJ, the most common sequences were $\mathrm{T}_{1}$-weighted spin-echo in combination with either a gadolinium sequence $[10,11,14]$ or a Short Tau Inversion Recovery (STIR) sequence [13]. The slice orientation was either semicoronal or semiaxial or a combination of both. In the spine, the MRI protocol consisted of fewer sequences. Three articles reported the use of sagittal $\mathrm{T}_{1}$-weighted spin-echo and STIR $[15,17,18]$, and one used only sagittal STIR [16]. None of the included studies evaluating the spine used contrast enhancement in the MRI protocol. For more details of the MRI protocols, see Table 5.

\section{Assessment of methodologic quality}

The quality score of the nine studies ranged from 1 to 7 points, with a mean score of 3.7. Two articles were rated more than 5 points and were considered of high quality $[13,16]$, and three articles were rated less than 3 points [10-12] (Table 1).

In relation to the description of the study samples, five articles did not fully describe both cases and noncases with respect to age, gender, and diagnosis $[11,14,15,17,18]$, three articles had no description of the sampling method used for the control groups $[11,17,18]$, and for two of these $[17,18]$, it was not clear whether these groups were included in the data analyses. Regarding the sampling

Table 4 Descriptive data for articles on MRI and SpA fulfilling the inclusion criteria

\begin{tabular}{|c|c|c|c|c|c|c|c|}
\hline & Study type & $\begin{array}{l}\text { Total } \\
\text { number }\end{array}$ & $\begin{array}{l}\text { Number of AS } \\
\text { patients (DD) }\end{array}$ & $\begin{array}{l}\text { Number of SpA } \\
\text { patients (DD) }\end{array}$ & $\begin{array}{l}\text { Number of IBP } \\
\text { patients (DD) }\end{array}$ & $\begin{array}{l}\text { Number of NILBP } \\
\text { patients (DD) }\end{array}$ & $\begin{array}{l}\text { Number of no } \\
\text { LBP patients }\end{array}$ \\
\hline \multicolumn{8}{|l|}{$\begin{array}{l}\text { Sacroiliac } \\
\text { joint }\end{array}$} \\
\hline $\begin{array}{l}\text { Bollow et al. } \\
(1995) \text { [10] }\end{array}$ & $\begin{array}{l}\text { Prospective } \\
\text { case-control }\end{array}$ & 125 & 36 (3.1 years) & 36 (5.9 years) & & 53 (5.7 years) & \\
\hline $\begin{array}{l}\text { Klauser et al. } \\
(2004)[11]\end{array}$ & $\begin{array}{l}\text { Prospective } \\
\text { case-control }\end{array}$ & 133 & & & 103 (NR) & & 30 \\
\hline $\begin{array}{l}\text { Brandt et al. } \\
(2007)[12]\end{array}$ & $\begin{array}{l}\text { Prospective } \\
\text { cohort }\end{array}$ & 158 & 32 (NR) & $58(N R)$ & & $68(\mathrm{NR})$ & \\
\hline $\begin{array}{l}\text { Weber et al. } \\
(2010) \text { [13] }\end{array}$ & $\begin{array}{l}\text { Prospective } \\
\text { case-control }\end{array}$ & 187 & 75 (6.1 years) & & 27 (29 mo) & $26(\mathrm{NR})$ & 59 \\
\hline $\begin{array}{l}\text { Wick et al. } \\
(2010) \text { [14] }\end{array}$ & $\begin{array}{l}\text { Retrospective } \\
\text { cohort }\end{array}$ & 156 & 27 (NR) & 101 (NR) & & $28(N R)$ & \\
\hline \multicolumn{8}{|l|}{ Spine } \\
\hline $\begin{array}{l}\text { Kim et al. } \\
\text { (2008) [15] }\end{array}$ & $\begin{array}{l}\text { Retrospective } \\
\text { case control }\end{array}$ & 104 & 52 (NR) & & & 52 (NR) & \\
\hline $\begin{array}{l}\text { Weber et al. } \\
(2009) \text { [16] }\end{array}$ & $\begin{array}{l}\text { Prospective } \\
\text { case-control }\end{array}$ & 85 & 35 (8 years) & & 25 (10 mo) & & 35 \\
\hline $\begin{array}{l}\text { Bennett et al. } \\
(2009)[17]\end{array}$ & $\begin{array}{l}\text { Retrospective } \\
\text { cohort }\end{array}$ & 185 & & 64 (8.5 years) & & 110 (NR) & 11 \\
\hline $\begin{array}{l}\text { Bennett et al. } \\
\text { (2009) [18] }\end{array}$ & $\begin{array}{l}\text { Retrospective } \\
\text { cohort }\end{array}$ & 185 & & 64 (8.5 years) & & 110 (NR) & 11 \\
\hline
\end{tabular}

MRI, magnetic resonance imaging; SpA, spondyloarthritis; AS, ankylosing spondylitis; $D D$, mean disease duration;

IBP, inflammatory back pain; NILBP, noninflammatory low-back pain; no LBP, no low-back pain; mo, months; NR, mean disease duration not reported. 
Table 5 Descriptive data for MRI technique used in the included articles

\begin{tabular}{|c|c|c|c|c|c|c|c|}
\hline & $\begin{array}{l}\text { Field } \\
\text { strength }\end{array}$ & $\begin{array}{l}\text { Sequence } \\
1\end{array}$ & Sequence 2 & Sequence 3 & Sequence 4 & Sequence 5 & Sequence 6 \\
\hline \multicolumn{8}{|l|}{ Sacroiliac joint } \\
\hline $\begin{array}{l}\text { Bollow et al. } \\
\text { (1995) [10] }\end{array}$ & $1.5 \mathrm{~T}$ & $\begin{array}{l}\text { Semi axial } \\
\mathrm{T}_{1} \mathrm{~W} \text { SE }\end{array}$ & $\begin{array}{l}\text { Dynamic } T_{2}^{*} W \\
\text { GRE, FLASH, }\end{array}$ & $\begin{array}{l}\text { Dynamic T2*W GRE, } \\
\text { FLASH, Gd }\end{array}$ & & & \\
\hline $\begin{array}{l}\text { Klauser et al. } \\
\text { (2004) [11] }\end{array}$ & $1.5 \mathrm{~T}$ & $\begin{array}{l}\text { Semi axial } \\
\mathrm{T}_{1} \mathrm{~W}, \mathrm{SE}\end{array}$ & $\begin{array}{l}\text { Semi axial } T_{2} w \\
\text { TSE }\end{array}$ & $\begin{array}{l}\text { Semi axial } T_{1} W_{\text {, SE }} \\
\text { FS }\end{array}$ & Semi cor. $T_{1} W_{\text {, }} S E$ & Semi cor. TIRM & $\begin{array}{l}\text { Semi axial + Semi cor. } \\
T_{1} W, S E, F S, G d\end{array}$ \\
\hline $\begin{array}{l}\text { Brandt et al. } \\
\text { (2007) [12] }\end{array}$ & ${ }^{\mathrm{a}} 1.5 \mathrm{~T}$ & NR & & & & & \\
\hline $\begin{array}{l}\text { Weber et al. } \\
\text { (2010) [13] }\end{array}$ & ${ }^{\mathrm{a}} 1.5 \mathrm{~T}$ & $\begin{array}{l}\text { Semi cor. } \\
T_{1} \text { w, SE }\end{array}$ & Semi cor. STIR & & & & \\
\hline $\begin{array}{l}\text { Wick et al. } \\
\text { (2010) [14] }\end{array}$ & $1.5 \mathrm{~T}$ & $\begin{array}{l}\text { Semi cor. } \\
\text { T1 w, SE }\end{array}$ & Semi cor. TIRM & $\begin{array}{l}\text { Semi cor. } T_{2} \text { w, } \\
\text { MEDIC FS }\end{array}$ & $\begin{array}{l}\text { Semi cor. + semi } \\
\text { axial T,W, SE, FS }\end{array}$ & $\begin{array}{l}\text { Semi axial T1, } \\
\text { SE, FS, Gd }\end{array}$ & Semi axial $T_{1} w, S E, G d$ \\
\hline \multicolumn{8}{|l|}{ Spine } \\
\hline $\begin{array}{l}\text { Kim et al. } \\
\text { (2008) [15] }\end{array}$ & $1.5 \mathrm{~T}$ & $\begin{array}{l}\text { Sagittal } T_{1} W \\
\text { SE }\end{array}$ & Sagittal $T_{2} \mathrm{~W}$ FSE & & & & \\
\hline $\begin{array}{l}\text { Weber et al. } \\
\text { (2009) [16] }\end{array}$ & $1.5 \mathrm{~T}$ & $\begin{array}{l}\text { Sagittal } \\
\text { turbo STIR }\end{array}$ & & & & & \\
\hline $\begin{array}{l}\text { Bennett et al. } \\
\text { (2009) [17] }\end{array}$ & ${ }^{\mathrm{a}} 1.5 \mathrm{~T}$ & $\begin{array}{l}\text { Sagittal } T_{1}, \\
\text { SE }\end{array}$ & Sagittal STIR & & & & \\
\hline $\begin{array}{l}\text { Bennett et al. } \\
\text { (2009) [18] }\end{array}$ & ${ }^{\mathrm{a}} 1.5 \mathrm{~T}$ & $\begin{array}{l}\text { Sagittal } \\
\mathrm{T}_{1} \mathrm{~W}, \mathrm{SE}\end{array}$ & Sagittal STIR & & & & \\
\hline
\end{tabular}

${ }^{a}$ Information on field strength not available in the articles. Data obtained by personal contact with authors. T, Tesla; w, weighted; SE, spin-echo; GRE, gradientecho; FLASH, fast low-angle shot; Semi cor, semicoronal; Gd, gadolinium; TSE, turbo spin-echo; FS, fat saturated; TRIM, turbo inversion recovery magnitude; NR, not reported; STIR, short tau inversion recovery; MEDIC, multi echo data image combination; PD, proton density; FSE, fast spin echo.

methods used, one article reported the use of consecutive sampling [16]. The remaining eight either failed to report on this aspect or used convenience samples. Matching was performed adequately in relation to age and sex in four $[10,13,15,16]$ of the five case-control studies. One study had a case group with a mean age that was more than 20 years older than that of the control group [11].

In relation to the diagnosis of the target condition, none of the nine articles tested the reproducibility of the clinical diagnosis. Diagnostic criteria were used as a reference standard in five articles $[10,11,13,15,16]$, expert opinion in three articles $[14,17,18]$, and both criteria and expert opinion in one article [12]. In four articles describing retrospective studies $[14,15,17,18]$, the independence of MRI from the clinical diagnosis was unclear. In one prospective study [12], which aimed to test referral recommendations, MRI was recognized as part of the diagnosis for the group of preradiographic SpA, thereby confounding the association observed. In seven articles $[10-12,14,15,17,18]$, inadequate or no reporting was made of blinding of the MRI results at the time of the clinical diagnosis.

In relation to the MRI evaluation, most studies had acceptable definitions of the MRI findings [13-18]. Five articles performed reproducibility tests of the MRI evaluation $[13,14,16-18]$, and five studies blinded the evaluation for the diagnosis [13-17]. None of the nine articles reported the time interval between MRI and diagnosis.
In relation to the statistical analysis, one article failed to report fully the CI, $P$ values, and/or raw data [10], and one article used an inappropriate statistical method for the types of data available [14]. Five articles had shortcomings in the way the results were presented $[10,12,14,17,18]$, such as uncertainties in relation to which groups were included in the calculation of the specificity $[17,18]$ and data primarily presented as graphics and per SIJ joint instead of per person [10].

\section{Association between MRI findings and the clinical diagnosis of SpA}

Because of a substantial heterogeneity in the included studies regarding the methodologic quality, the MRI findings, the MRI technique used, and the regions under evaluation, it was not possible to perform a meta-analysis, and we decided not to report data systematically. Instead, a descriptive assessment of the results based on the extracted data was performed. One article of high quality was found that evaluated the SIJ [13], and another article of high quality was found that evaluated the spine [16], both of which were from the same research team. A summary of the extracted data from these two studies is presented in Tables 6 and 7.

\section{Sacroiliac joint}

The study by Weber et al. from 2010 [13] included four groups in a prospective case-control study: 75 patients with AS included on the basis of the modified New York criteria [19], 27 patients with IBP based on the 
Table 6 Associations between MRI finding in the SIJ and the diagnosis of AS and IBP

\begin{tabular}{|c|c|c|c|c|c|c|}
\hline \multirow[t]{2}{*}{ MRI findings } & \multirow{2}{*}{$\begin{array}{l}\text { Sensitivity of MRI findings } \\
(95 \% \mathrm{Cl})\end{array}$} & \multirow{2}{*}{$\begin{array}{l}\text { Specificity of MRI findings } \\
(95 \% \mathrm{Cl})\end{array}$} & \multicolumn{2}{|c|}{ Cases, number } & \multicolumn{2}{|c|}{ Controls, number } \\
\hline & & & AS & IBP & NLSBP & No LBP \\
\hline $\mathrm{BMO}$ & $0.85(0.76-0.92)$ & $0.93(0.84-0.97)$ & 75 & & & 59 \\
\hline Erosions & $0.91(0.82-0.95)$ & $0.98(0.91-1.00)$ & 75 & & & 59 \\
\hline Fat infiltration & $0.91(0.82-0.95)$ & $0.86(0.76-0.93)$ & 75 & & & 59 \\
\hline Ankylosis & $0.27(0.18-0.38)$ & $1.00(0.94-1.00)$ & 75 & & & 59 \\
\hline Global assessment & 0.99 & 0.96 & 75 & & & 59 \\
\hline $\mathrm{BMO}$ & $0.85(0.76-0.92)$ & $0.77(0.58-0.89)$ & 75 & & 26 & \\
\hline Erosions & $0.91(0.82-0.95)$ & $0.96(0.81-0.99)$ & 75 & & 26 & \\
\hline Fat infiltration & $0.91(0.82-0.95)$ & $0.85(0.67-0.94)$ & 75 & & 26 & \\
\hline Ankylosis & $0.26(0.18-0.38)$ & $1.00(0.87-1.00)$ & 75 & & 26 & \\
\hline Global assessment & 0.99 & 0.92 & 75 & & 26 & \\
\hline$\overline{\mathrm{BMO}}$ & $0.67(0.48-0.81)$ & $0.93(0.84-0.97)$ & & 27 & & 59 \\
\hline Erosions & $0.48(0.31-0.66)$ & $0.98(0.91-1.00)$ & & 27 & & 59 \\
\hline Fat infiltration & $0.37(0.22-0.56)$ & $0.86(0.76-0.93)$ & & 27 & & 59 \\
\hline Global assessment & 0.52 & 0.96 & & 27 & & 59 \\
\hline $\mathrm{BMO}$ & $0.67(0.48-0.81)$ & $0.77(0.58-0.89)$ & & 27 & 26 & \\
\hline Erosions & $0.48(0.31-0.66)$ & $0.96(0.81-0.99)$ & & 27 & 26 & \\
\hline Fat infiltration & $0.37(0.22-0.56)$ & $0.85(0.67-0.94)$ & & 27 & 26 & \\
\hline Global assessment & 0.52 & 0.92 & & 27 & 26 & \\
\hline
\end{tabular}

Results from Weber et al. (2010). Sensitivity and specificity based on concordant observations of a minimum of two of five readers. $95 \% \mathrm{Cl}$ calculated from raw data. MRI, magnetic resonance imaging; SIJ, sacroiliac joint; AS, ankylosing spondylitis; IBP, inflammatory back pain; Cl, confidence interval; NSLBP, nonspecific low-back pain; BMO, bone marrow edema; global assessments, 95\% Cl not possible to calculate, because of no raw data.

Table 7 Associations between MRI finding in the spine and the diagnosis of AS and IBP

\begin{tabular}{|c|c|c|c|c|c|}
\hline \multirow[t]{2}{*}{ MRI findings } & \multirow{2}{*}{$\begin{array}{l}\text { Sensitivity of MRI findings } \\
(95 \% \mathrm{Cl})\end{array}$} & \multirow{2}{*}{$\begin{array}{l}\text { Specificity of MRI findings } \\
(95 \% \mathrm{Cl})\end{array}$} & \multicolumn{2}{|c|}{ Cases, number } & \multirow{2}{*}{$\begin{array}{l}\text { Controls, number } \\
\text { No LBP } \\
\end{array}$} \\
\hline & & & $\overline{\mathrm{AS}}$ & IBP & \\
\hline$\geq 1 \mathrm{ClL}$ & $0.77(0.61-0.88)$ & $0.77(0.61-0.88)$ & 35 & & 35 \\
\hline$\geq 2 \mathrm{CIL}$ & $0.69(0.52-0.81)$ & $0.94(0.81-0.98)$ & 35 & & 35 \\
\hline$\geq 3 \mathrm{CIL}$ & $0.66(0.49-0.79)$ & $0.94(0.81-0.98)$ & 35 & & 35 \\
\hline$\geq 1 \mathrm{tCIL}$ & $0.69(0.52-0.81)$ & $0.83(0.67-0.92)$ & 35 & & 35 \\
\hline$\geq 2 \mathrm{tCIL}$ & $0.57(0.41-0.72)$ & $0.94(0.81-0.98)$ & 35 & & 35 \\
\hline$\geq 3 \mathrm{tClL}$ & $0.46(0.30-0.62)$ & $0.97(0.85-0.99)$ & 35 & & 35 \\
\hline$\geq 1 \mathrm{ICIL}$ & $0.51(0.36-0.67)$ & $0.94(0.81-0.98)$ & 35 & & 35 \\
\hline$\geq 1 \mathrm{NIL}$ & $0.06(0.02-0.19)$ & $0.97(0.85-0.99)$ & 35 & & 35 \\
\hline$\geq 1 \mathrm{LIL}$ & $0.31(0.19-0.48)$ & $0.97(0.85-0.99)$ & 35 & & 35 \\
\hline$\geq 1 \mathrm{FIL} / \mathrm{PIL}$ & $0.09(0.03-0.22)$ & $1.00(0.90-1.00)$ & 35 & & 35 \\
\hline$\geq 1 \mathrm{ClL}$ & $0.40(0.23-0.59)$ & $0.88(0.70-0.96)$ & & 25 & 25 \\
\hline$\geq 2 \mathrm{ClL}$ & $0.32(0.17-0.52)$ & $0.96(0.80-0.99)$ & & 25 & 25 \\
\hline$\geq 3 \mathrm{CIL}$ & $0.12(0.04-0.30)$ & $0.96(0.80-0.99)$ & & 25 & 25 \\
\hline$\geq 1 \mathrm{tClL}$ & $0.32(0.17-0.52)$ & $0.88(0.70-0.96)$ & & 25 & 25 \\
\hline$\geq 2 \mathrm{tClL}$ & $0.24(0.11-0.43)$ & $0.96(0.80-0.99)$ & & 25 & 25 \\
\hline$\geq 3 \mathrm{tClL}$ & $0.12(0.04-0.30)$ & $0.96(0.80-0.99)$ & & 25 & 25 \\
\hline$\geq 1 \mathrm{ICIL}$ & $0.24(0.11-0.43)$ & $1.00(0.87-1.00)$ & & 25 & 25 \\
\hline$\geq 1 \mathrm{NIL}$ & $0.04(0.01-0.20)$ & $0.96(0.80-0.99)$ & & 25 & 25 \\
\hline$\geq 1 \mathrm{ICIL}$ & $0.12(0.04-0.30)$ & $0.96(0.80-0.99)$ & & 25 & 25 \\
\hline$\geq 1 \mathrm{FIL} / \mathrm{PIL}$ & $0.00(0.00-0.13)$ & $1.00(0.87-1.00)$ & & 25 & 25 \\
\hline
\end{tabular}

Sensitivity and specificity based on concordant observations of three readers; results from Weber et al. (2009). AS, Ankylosing spondylitis; IBP, inflammatory back pain; no LBP, no low-back pain; CIL, vertebral corner inflammatory lesion; tCIL, thoracic CIL; ICIL lumbar CIL; NIL, vertebral noncorner inflammatory lesion; LIL, lateral inflammatory lesion; FIL/PIL, facet or other posterior element inflammatory lesion. 
Calin Criteria [20] or the Berlin Criteria [21], 26 patients with NSLBP, and 59 healthy controls without back pain. The AS patients had a mean disease duration of 6.1 years, and IBP patients had a mean disease duration of 29 months. Disease duration for the NSLBP patients was not reported.

The MRI findings under evaluation were bone marrow edema (BMO), erosions, fat infiltration, global assessment of sacroiliitis, and ankylosis. Positive associations for BMO, erosions, fat infiltration, and global assessment of sacroiliitis were shown for both AS and IBP patients when compared with the NSLBP and no-LBP groups. Ankylosis was found in only the AS patients, in 20 of 75 patients $(26.7 \%)$. In general, the highest combined values of sensitivity and specificity were found when comparing AS patients with the healthy controls, and the lowest values were found when comparing IBP with NSLBP (Table 6).

Interestingly, BMO lesions, as defined in the ASAS diagnostic criteria [8], were found to be relatively frequent in NSLBP and were reported in 6 (23.1\%) of 26 subjects and less frequently in healthy controls, with 4 $(6.8 \%)$ of 59 subjects.

\section{Spine}

The study by Weber et al. from 2009 [16] compared 35 patients with AS fulfilling the modified New York criteria [19], 25 patients with IBP, who fulfilled the Berlin criteria [21] and who also had one or more characteristic SpA features, and 35 healthy controls without back pain in a prospective case-control study. The AS patients had a mean disease duration of 8.0 years and the IBP patients had a mean disease duration of 10 months.

The MRI findings under evaluation were BMO lesions of varied number and location in the spine. When comparing AS patients with healthy controls, a number of positive associations were identified for BMO lesions in vertebral corners and in the lateral spine. When comparing IBP patients with healthy controls, the associations were seen to decrease (see Table 7 for details).

\section{Discussion}

\section{Summary of main results}

The results of the review show that a positive association exists between certain MRI findings in the axial skeleton and the diagnosis of both AS and IBP. However, these results are based on only two high-quality studies, and the amount of relevant data was insufficient to give a reliable quantification of this association.

\section{Implications for research}

On the basis of the identified methodologic shortcomings of the included articles, this review highlights important issues that should be taken into consideration when conducting studies with the aim of evaluating the diagnostic utility of MRI in the diagnosis of SpA. The following issues will be discussed in the subsequent text: Size of the study sample, selecting the proper study population, sampling method of the study cohort, independence of MRI from the reference standard, reproducibility testing of both the reference standard and the MRI evaluation, and standardization of the MRI findings.

In this review, the inclusion criterion for the size of study samples was set to a minimum of 20 subjects per group. This was because a small sample size often gives imprecise estimates of diagnostic accuracy. For example, when the number of patients with SpA is 20, the twosided $95 \%$ CI of a sensitivity of $80 \%$ is $58 \%$ to $92 \%$. This is, however, still a very wide CI, and because wide CIs make it difficult to determine how informative the results of the study are, we would recommend that future studies use larger sample size. For example, if the number of patients with SpA is 200, the two-sided 95\% CI of a sensitivity of $80 \%$ is $74 \%$ to $85 \%$.

When choosing the study sample, it is crucial that an effort be made to make it as comparable to the population seen in a clinical setting as possible. Not surprisingly, the results from the two high-quality studies show that the association was stronger between patients with AS and asymptomatic people than the association between IBP patients and patients with NSLBP $[13,16]$. However, for the clinician, the challenge will often be differentiating between IBP and NSLBP. When investigating the diagnostic utility of MRI in SpA, it is therefore important that the study samples be representative of "real" patient populations, instead of comparing patients with longlasting disease and asymptomatic persons. Furthermore, one of the high-quality studies reports inflammatory MRI findings in the SIJ to be relatively common in patients with NSLBP [13]. Because the specificity is estimated entirely from results from the group of noncases or controls, this, additionally, underlines the need for further evaluation of the presence of MRI findings also in patients with NSLBP.

The sampling methods used in the included studies were either insufficient or not fully described in the majority of the studies, which makes it difficult to preclude selection bias. It is mandatory when conducting studies on diagnostic accuracy that both the sampling method and the study sample are well described, that the selection of study participants is performed systematically and unselectively, and, for case-control studies, that the two groups are comparable except for the target condition. Furthermore, in some of the articles identified in this review, the importance of the controls seemed to be underestimated, even though the sampling and description of the controls are just as important as the sampling and description of the cases.

That no objective gold standard exists for the diagnosis of SpA, which is instead based on a composite 
clinical presentation, constrains the possibilities for the evaluation of the diagnostic accuracy of MRI. However, it is indisputable that when evaluating a diagnostic test, independent evaluation of the index test and the reference standard is essential. When MRI is used in the decision making of the clinical diagnosis, as seen in more than half of the included studies, incorporation bias is highly likely. This was predominantly a problem in the included retrospective studies. The fact that MRI is widely used in the diagnosis of SpA restricts the possibilities of conducting meaningful retrospective studies on the diagnostic accuracy of MRI.

One way to strengthen the reliability of the diagnosis is to test the reproducibility of the selected reference standard. However, none of the nine included articles tested the reproducibility of the clinical diagnosis. Another way to strengthen the reliability of the diagnosis would be to include a longitudinal aspect and to follow the development of more-advanced disease stages to confirm the diagnosis. Even though several longitudinal studies were identified in this review, none met the inclusion criteria, usually because either no or too few controls were used.

Several activity scores for inflammatory and structural MRI findings have been developed; however, no international consensus exists about the definition of diagnostic MRI findings, which was a factor in our review. In general, the included studies contained definitions of the MRI findings. However, little homogeneity existed in these definitions, and only five of the nine articles reported testing of the reproducibility of the MRI evaluation. Before testing the diagnostic utility of an MRI finding, it is necessary to define the MRI finding and further to present acceptably reproducible test results. Furthermore, an experienced musculoskeletal radiologist should be part of the conduct and testing of the evaluation protocol. An international agreement on definitions of different MRI findings and a threshold minimal reproducibility would facilitate both the translation from research to clinical practice and a comparison with future research results.

In summary, the optimal design for future studies that investigate the utility of MRI in the early diagnosis of SpA is a large longitudinal clinical cohort study that recruits participants consecutively and includes patients with NSLBP. Furthermore, a well-defined clinical diagnosis based on consensus criteria and blinded for MRI should be used as a reference standard. Similarly, a validated MRI evaluation with clear definitions blinded to the clinical information should be used for the MRI evaluation.

\section{Application of findings to clinical practice}

The literature search associated with the current review revealed no other systematic critical review on the utility of MRI in the diagnosis of SpA. However, a large number of commentaries and narrative reviews with or without transparent search strategies have been published, in which it seems that the majority report a positive view of the value of MRI in the diagnosis of SpA. The obvious need for optimization of the diagnostic process of SpA may have contributed to the positive perception that has developed regarding MRI as a tool in the SpA diagnosis. The fact that MRI of the SIJ is included in the new diagnostic criteria developed by ASAS [8] has led to further optimism in relation to the diagnostic process of SpA. However, on the basis of the results from the current review, the limited number of high-quality studies on the diagnostic utility of MRI in SpA should preclude MRI being seen as the new gold standard in the diagnosis of SpA. If inflammatory and structural MRI findings are interpreted as being more specific for SpA than the research can support, a real risk exists of SpA being overdiagnosed.

As mentioned earlier, to be able to make a reasonable translation of research results to clinical practice, the representativeness of the study sample to clinical practice and the standardization and validation of the MRI evaluation is important. However, it also is essential that the MRI protocols used in the studies are relatively easy to implement and constitute the least health risk for the patients. Three of the studies included in this review used gadolinium contrast-enhanced sequences. However, for future studies, the necessity of gadolinium should be carefully considered, because other techniques, such as STIR, have shown a similar capability of visualizing BMO $[22,23]$, and the use of contrast is more invasive, expensive, and time consuming than is a noncontrast method. Furthermore, a small but serious risk of contrast medium-induced nephrotoxicity exists [24], which also must be taken into consideration.

\section{Strengths and weaknesses of the review}

The strength of the current review is the systematic search method and the rigorous assessment of the methodologic quality of the included studies. To our knowledge, this review is the first to give an overview of the level of evidence of the diagnostic utility of MRI, including a quality assessment.

The weaknesses of the review are first, the possibility of relevant articles not being included because of the language limitations, and second, the limited number of databases used in the search. Furthermore, it might be argued that the threshold for a minimal study sample size was either too low or too high. However, it seems reasonable to reduce the width of the $95 \%$ CI by not setting the cut-point too low; in contrast, increasing the cut-point for sample size further would have greatly decreased the number of relevant articles that could be included. 


\section{Conclusion}

Bone marrow edema, erosions, fat infiltrations, global assessment of sacroiliitis, and ankylosis on MRI were found to be associated with SpA. However, because only two high-quality studies were identified, it was not possible to perform a meta-analytic quantification of the association. The current systematic critical review illustrates that only limited evidence exists of the utility of MRI in the diagnosis of SpA. However, MRI is already widely used in clinical practice, and therefore, a strong need exists for more high-quality studies, cross-sectional as well as longitudinal, without the shortcomings of the previous work identified in this review. In the meantime, caution is needed to avoid overdiagnosing SpA.

\section{Abbreviations}

AS: ankylosing spondylitis; ASAS: Assessment of SpondyloArthritis international Society; BMO: bone marrow edema; Cl: confidence interval; IBP: inflammatory back pain; MRI: magnetic resonance imaging; NSLBP: nonspecific low-back pain; SIJ: sacroiliac joint; SpA: spondyloarthritis.

\section{Acknowledgements}

The authors thank Suzanne Capell, academic editor, for proofreading, and Associate Professor Peter Kent for comments on earlier versions of this manuscript. The work was supported by grants from the Danish Foundation of Chiropractic Research and Postgraduate Education.

\section{Author details}

${ }^{1}$ Research Department, Spine Centre of Southern Denmark, Hospital Lillebaelt, Clinical Locomotion Network, Oestre Hougvej 55, Middelfart 5500, Denmark. ${ }^{2}$ Institute of Regional Health Services Research, University of Southern Denmark,Winsloewparken 19, Odense C 5000, Denmark.

\section{Authors' contributions}

BA conducted the collection, analyses, and interpretation of the data, and drafted the manuscript. TSJ participated in the collection, interpretation and analyses of the data and helped to draft the manuscript. CLY participated in the interpretation of data and provided editorial assistance. All authors were an integral part of the study design and critically reviewed, contributed to, and approved the final manuscript.

\section{Competing interests}

The authors declare that they have no competing interests.

Received: 5 April 2011 Revised: 21 February 2012

Accepted: 9 March 2012 Published: 9 March 2012

\section{References}

1. Akkoc N: Are spondyloarthropathies as common as rheumatoid arthritis worldwide? A review. Curr Rheumatol Rep 2008, 10:371-378.

2. Barkham N, Keen HI, Coates LC, O'Connor P, Hensor E, Fraser AD, Cawkwell LS, Bennett A, McGonagle D, Emery P: Clinical and imaging efficacy of infliximab in HLA-B27-positive patients with magnetic resonance imaging-determined early sacroiliitis. Arthritis Rheum 2009, 60:946-954.

3. Haibel H, Rudwaleit M, Listing J, Heldmann F, Wong RL, Kupper H, Braun J, Sieper J: Efficacy of adalimumab in the treatment of axial spondylarthritis without radiographically defined sacroiliitis: results of a twelve-week randomized, double-blind, placebo-controlled trial followed by an open-label extension up to week fifty-two. Arthritis Rheum 2008, 58:1981-1991.

4. Underwood MR, Dawes $\mathrm{P}$ : Inflammatory back pain in primary care. $\mathrm{Br} J$ Rheumatol 1995, 34:1074-1077.
5. Mau W, Zeidler H, Mau R, Majewski A, Freyschmidt J, Stangel W, Deicher H: Clinical features and prognosis of patients with possible ankylosing spondylitis: results of a 10-year followup. J Rheumato/ 1988, 15:1109-1114.

6. Ahlstrom H, Feltelius N, Nyman R, Hallgren R: Magnetic resonance imaging of sacroiliac joint inflammation. Arthritis Rheum 1990, 33:1763-1769.

7. Bennett AN, McGonagle D, O'Connor P, Hensor EM, Sivera F, Coates LC, Emery $\mathrm{P}$, Marzo-Ortega $\mathrm{H}$ : Severity of baseline magnetic resonance imaging-evident sacroiliitis and HLA-B27 status in early inflammatory back pain predict radiographically evident ankylosing spondylitis at eight years. Arthritis Rheum 2008, 58:3413-3418.

8. Rudwaleit M, van der HD, Landewe R, Listing J, Akkoc N, Brandt J, Braun J, Chou CT, Collantes-Estevez E, Dougados M, Huang F, Gu J, Khan MA, Kirazli Y, Maksymowych WP, Mielants H, Sørensen IJ, Ozgocmen S, Roussou E, Valle-Oñate R, Weber U, Wei J, Sieper J: The Development of Assessment of SpondyloArthritis international Society (ASAS) Classification Criteria for Axial Spondyloarthritis (Part II): validation and final selection. Ann Rheum Dis 2009, 68:777-783.

9. Whiting P, Rutjes AW, Reitsma JB, Bossuyt PM, Kleijnen J: The development of QUADAS: a tool for the quality assessment of studies of diagnostic accuracy included in systematic reviews. BMC Med Res Methodol 2003, 3:25.

10. Bollow M, Braun J, Hamm B, Eggens U, Schilling A, Konig H, Wolf KJ: Early sacroiliitis in patients with spondyloarthropathy: evaluation with dynamic gadolinium-enhanced MR imaging. Radiology 1995, 194:529-536.

11. Klauser A, Halpern EJ, Frauscher F, Gvozdic D, Duftner C, Springer P, Schirmer M: Inflammatory low back pain: high negative predictive value of contrast-enhanced color Doppler ultrasound in the detection of inflamed sacroiliac joints. Arthritis Rheum 2005, 53:440-444.

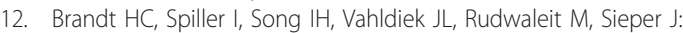
Performance of referral recommendations in patients with chronic back pain and suspected axial spondyloarthritis. Ann Rheum Dis 2007, 66:1479-1484

13. Weber U, Lambert RG, Ostergaard M, Hodler J, Pedersen SJ, Maksymowych WP: The diagnostic utility of MRI in spondyloarthritis: an international multicentre evaluation of 187 subjects (The MORPHO study). Arthritis Rheum 2010, 62:3948-3058.

14. Wick MC, Weiss RJ, Jaschke W, Klauser AS: Erosions are the most relevant magnetic resonance imaging features in quantification of sacroiliac joints in ankylosing spondylitis. J Rheumatol 2010, 37:622-627.

15. Kim NR, Choi JY, Hong SH, Jun WS, Lee JW, Choi JA, Kang HS: "MR corner sign": value for predicting presence of ankylosing spondylitis. AJR Am J Roentgenol 2008, 191:124-128.

16. Weber U, Hodler J, Kubik RA, Rufibach K, Lambert RG, Kissling RO, Pfirrmann CW, Maksymowych WP: Sensitivity and specificity of spinal inflammatory lesions assessed by whole-body magnetic resonance imaging in patients with ankylosing spondylitis or recent-onset inflammatory back pain. Arthritis Rheum 2009, 61:900-908.

17. Bennett AN, Rehman A, Hensor EM, Marzo-Ortega H, Emery P, McGonagle D: Evaluation of the diagnostic utility of spinal magnetic resonance imaging in axial spondylarthritis. Arthritis Rheum 2009, 60:1331-1341.

18. Bennett AN, Rehman A, Hensor EM, Marzo-Ortega H, Emery P, McGonagle DG: The fatty Romanus lesion: a non-inflammatory spinal MRI lesion specific for axial-spondyloarthropathy. Ann Rheum Dis 2009, 69:891-894.

19. van der LS, Valkenburg HA, Cats A: Evaluation of diagnostic criteria for ankylosing spondylitis: a proposal for modification of the New York criteria. Arthritis Rheum 1984, 27:361-368.

20. Calin A, Porta J, Fries JF, Schurman DJ: Clinical history as a screening test for ankylosing spondylitis. JAMA 1977, 237:2613-2614.

21. Rudwaleit M, Metter A, Listing J, Sieper J, Braun J: Inflammatory back pain in ankylosing spondylitis: a reassessment of the clinical history for application as classification and diagnostic criteria. Arthritis Rheum 2006, 54:569-578.

22. Baraliakos $X$, Hermann KG, Landewe R, Listing J, Golder W, Brandt J, Rudwaleit M, Bollow M, Sieper J, van der Heijde D, Braun J: Assessment of acute spinal inflammation in patients with ankylosing spondylitis by magnetic resonance imaging: a comparison between contrast enhanced $\mathrm{T} 1$ and short tau inversion recovery (STIR) sequences. Ann Rheum Dis 2005, 64:1141-1144. 
23. Madsen KB, Egund N, Jurik AG: Grading of inflammatory disease activity in the sacroiliac joints with magnetic resonance imaging: comparison between short-tau inversion recovery and gadolinium contrastenhanced sequences. J Rheumatol 2010, 37:393-400.

24. Thomsen HS: Guidelines for contrast media from the European Society of Urogenital Radiology. AJR Am J Roentgenol 2003, 181:1463-1471.

25. Algin O, Gokalp G, Baran B, Ocakoglu G, Yazici Z: Evaluation of sacroiliitis: contrast-enhanced MRI with subtraction technique. Skeletal Radiol 2009, 38:983-988.

26. Algin O, Gokalp G, Ocakoglu G: Evaluation of bone cortex and cartilage of spondyloarthropathic sacroiliac joint: efficiency of different fat-saturated MRI sequences (T1-weighted, 3D-FLASH, and 3D-DESS). Acad Radiol 2010, 17:1292-1298

27. Baraliakos X, Landewe R, Hermann KG, Listing J, Golder W, Brandt J, Rudwaleit M, Bollow M, Sieper J, van der Heijde D, Braun J: Inflammation in ankylosing spondylitis: a systematic description of the extent and frequency of acute spinal changes using magnetic resonance imaging. Ann Rheum Dis 2005, 64:730-734.

28. Bejia I, Younes M, Zrour S, Touzi M, Bergaoui N: Factors predicting outcomes of mechanical sciatica: A review of 1092 cases. Joint Bone Spine 2004, 71:567-571.

29. Blum U, Buitrago-Tellez C, Mundinger A, Krause T, Laubenberger J, Vaith P, Peter HH, Langer M: Magnetic resonance imaging (MRI) for detection of active sacroiliitis: a prospective study comparing conventional radiography, scintigraphy, and contrast enhanced MRI. J Rheumatol 1996, 23:2107-2115.

30. Bochkova AG, Levshakova AV, Bunchuk NV, Braun J: Spinal inflammation lesions as detected by magnetic resonance imaging in patients with early ankylosing spondylitis are more often observed in posterior structures of the spine. Rheumatology (Oxford) 2010, 49:749-755.

31. Bollow M, Konig H, Hoffmann C, Schilling A, Wolf $\mathrm{KJ}$ : [Initial findings using dynamic magnetic resonance tomography in the diagnosis of inflammatory diseases of the sacroiliac joint]. Rofo 1993, 159:315-324.

32. Bollow M, Braun J, Konig H, Schilling A, Wacker F, Seyrekbasan VF, Eggens $U$, Wolf $\mathrm{K}$ : [Dynamic magnetic resonance tomography of the sacroiliac joint: diagnosis of the early stages of a sacroiliitis]. Rontgenpraxis 1994, 47:70-77.

33. Bozgeyik Z, Ozgocmen S, Kocakoc E: Role of diffusion-weighted MRI in the detection of early active sacroiliitis. AJR Am J Roentgenol 2008 191:980-986.

34. Braun J, Bollow M, Eggens U, Konig H, Distler A, Sieper J: Use of dynamic magnetic resonance imaging with fast imaging in the detection of early and advanced sacroiliitis in spondylarthropathy patients. Arthritis Rheum 1994, 37:1039-1045.

35. Braun J, Bollow M, Remlinger G, Eggens U, Rudwaleit M, Distler A, Sieper J: Prevalence of spondylarthropathies in HLA-B27 positive and negative blood donors. Arthritis Rheum 1998, 41:58-67.

36. Bredella MA, Steinbach LS, Morgan S, Ward M, Davis JC: MRI of the sacroiliac joints in patients with moderate to severe ankylosing spondylitis. AJR Am J Roentgenol 2006, 187:1420-1426.

37. Chung HY, Machado P, van der HD, D'Agostino MA, Dougados M: HLA-B27 positive patients differ from HLA-B27 negative patients in clinical presentation and imaging: results from the DESIR cohort of patients with recent onset axial spondyloarthritis. Ann Rheum Dis 2011, 70:1930-1936.

38. Docherty P, Mitchell MJ, MacMillan L, Mosher D, Barnes DC, Hanly JG: Magnetic resonance imaging in the detection of sacroiliitis. J Rheumatol 1992, 19:393-401.

39. Friedburg H, Meske S, Hennig J, Billmann P, Peter HH, Wenz W: [Nuclear magnetic resonance tomography of the sacroiliac joint: a new examination technic in the differential diagnosis of rheumatic diseases of the lumbosacral transition]. Radiologe 1987, 27:130-134

40. Gleeson TG, O'Connell MJ, Duke D, Ryan M, Ennis R, Eustace SJ: Coronal oblique turbo STIR imaging of the sacrum and sacroiliac joints at routine MR imaging of the lumbar spine. Emerg Radiol 2005, 12:38-43.

41. Gupta AD: Sacroiliac joint pathologies in low back pain. J Back Musculoskelet Rehabil 2009, 22:91-97.

42. Hanly JG, Mitchell MJ, Barnes DC, MacMillan L: Early recognition of sacroiliitis by magnetic resonance imaging and single photon emission computed tomography. J Rheumatol 1994, 21:2088-2095.

43. Heuft-Dorenbosch L, Landewe R, Weijers R, Wanders A, Houben H, van der $L S$, van der HD: Combining information obtained from magnetic resonance imaging and conventional radiographs to detect sacroiliitis in patients with recent onset inflammatory back pain. Ann Rheum Dis 2006, 65:804-808.

44. Heuft-Dorenbosch L, Weijers R, Landewe R, van der LS, van der HD: Magnetic resonance imaging changes of sacroiliac joints in patients with recent-onset inflammatory back pain: inter-reader reliability and prevalence of abnormalities. Arthritis Res Ther 2006, 8:R11.

45. Heuft-Dorenbosch L, Landewe R, Weijers R, Houben $H$, van der LS, Jacobs $P$, van der HD: Performance of various criteria sets in patients with inflammatory back pain of short duration: the Maastricht early spondyloarthritis clinic. Ann Rheum Dis 2007, 66:92-98.

46. Inanc N, Atagunduz P, Sen F, Biren T, Turoglu HT, Direskeneli H: The investigation of sacroiliitis with different imaging techniques in spondyloarthropathies. Rheumatol Int 2005, 25:591-594.

47. Jevtic V, Rozman B, Kos-Golja M, Watt I: [MR imaging in seronegative spondyloarthritis]. Radiologe 1996, 36:624-631.

48. Liao Z, Gu J, Huang F, Lin Z, Zhao L, Yu B: Verification of Berlin algorithm for diagnosing undifferentiated spondyloarthropathy patients in Chinese population. Joint Bone Spine 2009, 76:146-149.

49. Liao Z, Lin Z, Xu M, Hu Z, Li T, Wei Q, Cao S, Huang J, Pan Y, Wu Y, Gu J: Clinical features of axial undifferentiated spondyloarthritis (USpA) in China: HLA-B27 is more useful for classification than MRI of the sacroiliac joint. Scand J Rheumatol 2011, 40:439-443.

50. Luukkainen RK, Virtanen $\mathrm{KO}$, Kaarela K: Occurrence of sacroiliitis in patients with seronegative oligoarthritis. Clin Rheumatol 2007, 26:715-717.

51. Marc V, Dromer C, Le GP, Manelfe C, Fournie B: Magnetic resonance imaging and axial involvement in spondylarthropathies: delineation of the spinal entheses. Rev Rheum Engl Ed 1997, 64:465-473.

52. McNally EG, Wilson DJ, Ostlere SJ: Limited magnetic resonance imaging in low back pain instead of plain radiographs: experience with first 1000 cases. Clin Radiol 2001, 56:922-925.

53. Muche B, Bollow M, Francois RJ, Sieper J, Hamm B, Braun J: Anatomic structures involved in early- and late-stage sacroiliitis in spondylarthritis: a detailed analysis by contrast-enhanced magnetic resonance imaging. Arthritis Rheum 2003, 48:1374-1384.

54. Murphey MD, Wetzel LH, Bramble JM, Levine E, Simpson KM, Lindsley HB: Sacroiliitis: MR imaging findings. Radiology 1991, 180:239-244.

55. Orchard TR, Holt H, Bradbury L, Hammersma J, McNally E, Jewell DP, Wordsworth BP: The prevalence, clinical features and association of HLAB27 in sacroiliitis associated with established Crohn's disease. Aliment Pharmacol Ther 2009, 29:193-197.

56. Peterova V, Forejtova S, Pavelka K: Correlation of some MR findings in ankylosing spondylitis. Prague Med Rep 2006, 107:26-36.

57. Puhakka KB, Jurik AG, Egund N, Schiottz-Christensen B, StengaardPedersen $\mathrm{K}$, van Overeem HG, Christiansen JV: Imaging of sacroiliitis in early seronegative spondylarthropathy: assessment of abnormalities by MR in comparison with radiography and CT. Acta Radiol 2003, 44:218-229.

58. Remy $M$, Bouillet $P$, Bertin $P$, Leblanche AF, Bonnet $C$, Pascaud $J L$, Boncoeur-Martel MP, Treves R: Evaluation of magnetic resonance imaging for the detection of sacroiliitis in patients with early seronegative spondylarthropathy. Rev Rheum Engl Ed 1996, 63:577-583.

59. Rennie WJ, Dhillon SS, Conner-Spady B, Maksymowych WP, Lambert RG: Magnetic resonance imaging assessment of spinal inflammation in ankylosing spondylitis: standard clinical protocols may omit inflammatory lesions in thoracic vertebrae. Arthritis Rheum 2009, 61:1187-1193.

60. Rudwaleit M, Landewe R, van der HD, Listing J, Brandt J, Braun J, BurgosVargas R, Collantes-Estevez E, Davis J, Dijkmans B, Dougados M, Emery P, van der Horst-Bruinsma IE, Inman R, Khan MA, Leirisalo-Repo M, van der Linden S, Maksymowych WP, Mielants H, Olivieri I, Sturrock R, de Vlam K Sieper J: The Development of Assessment of SpondyloArthritis international Society (ASAS) Classification Criteria for Axial Spondyloarthritis (Part I): Classification of paper patients by expert opinion including uncertainty appraisal. Ann Rheum Dis 2009, 68:770-776.

61. Rudwaleit M, Jurik AG, Hermann KG, Landewe R, van der HD, Baraliakos X Marzo-Ortega H, Ostergaard M, Braun J, Sieper J: Defining active sacroiliitis on magnetic resonance imaging (MRI) for classification of axial spondyloarthritis: a consensual approach by the ASAS/OMERACT MRI Group. Ann Rheum Dis 2009, 68:1520-1527.

62. Sreedhar C, Sree RM, Alam A, Indrajit I, Shanmuganandan K: Sacroiliitis in routine MRI for low back ache. Indian J Radiol Imaging 2006, 16:643-649. 
63. Weber U, Pfirrmann CW, Kissling RO, Hodler J, Zanetti M: Whole body MR imaging in ankylosing spondylitis: a descriptive pilot study in patients with suspected early and active confirmed ankylosing spondylitis. BMC Musculoskel Disord 2007, 8:20.

64. Weber U, Lambert RG, Pedersen SJ, Hodler J, Ostergaard M, Maksymowych WP: Assessment of structural lesions in sacroiliac joints enhances diagnostic utility of MRI in early spondyloarthritis. Arthritis Care Res (Hoboken) 2010, 62:1763-1771.

65. Weckbach S, Schewe S, Michaely HJ, Steffinger D, Reiser MF, Glaser C: Whole-body MR imaging in psoriatic arthritis: additional value for therapeutic decision making. Eur J Radiol 2009, 77:149-155.

66. Wienands K, Lukas P, Albrecht HJ: MR-imaging of spondylodiscitis in ankylosing spondylitis: clinical significance. [German]. Z Rheumatol 1990 49:356-360.

67. Williamson L, Dockerty $J$, Dalbeth N, McNally E, Ostlere S, Wordsworth BP: Clinical assessment of sacroiliitis and HLA-B27 are poor predictors of sacroiliitis diagnosed by magnetic resonance imaging in psoriatic arthritis. Rheumatology (Oxford) 2004, 43:85-88

68. Wittram C, Whitehouse GH, Bucknall RC: Fat suppressed contrast enhanced MR imaging in the assessment of sacroiliitis. Clin Radiol 1996, 51:554-558.

69. Wittram C, Whitehouse GH, Williams JW, Bucknall RC: A comparison of MR and CT in suspected sacroiliitis. J Comput Assist Tomogr 1996, 20:68-72.

70. Yu W, Feng F, Dion E, Yang H, Jiang M, Genant HK: Comparison of radiography, computed tomography and magnetic resonance imaging in the detection of sacroiliitis accompanying ankylosing spondylitis. Skeletal Radiol 1998, 27:311-320.

71. Althoff CE, Feist E, Burova E, Eshed I, Bollow M, Hamm B, Hermann KG: Magnetic resonance imaging of active sacroiliitis: do we really need gadolinium? Eur J Radiol 2009, 71:232-236.

72. Aydin SZ, Maksymowych WP, Bennett AN, McGonagle D, Emery P, MarzoOrtega $\mathrm{H}$ : Validation of the ASAS criteria and definition of a positive MRI of the sacroiliac joint in an inception cohort of axial spondyloarthritis followed up for 8 years. Ann Rheum Dis 2011, 71:55-60.

73. Baraliakos X, Listing J, Rudwaleit M, Sieper J, Braun J: The relationship between inflammation and new bone formation in patients with ankylosing spondylitis. Arthritis Res Ther 2008, 10:R104.

74. Battafarano DF, West SG, Rak KM, Fortenbery EJ, Chantelois AE: Comparison of bone scan, computed tomography, and magnetic resonance imaging in the diagnosis of active sacroiliitis. Semin Arthritis Rheum 1993, 23:161-176.

75. Bigot J, Loeuille D, Chary-Valckenaere I, Pourel J, Cao MM, Blum A: [Determination of the best diagnostic criteria of sacroiliitis with MRI]. J Radiol 1999, 80:1649-1657.

76. Brandt J, Bollow M, Haberle J, Rudwaleit M, Eggens U, Distler A, Sieper J, Braun J: Studying patients with inflammatory back pain and arthritis of the lower limbs clinically and by magnetic resonance imaging: many, but not all patients with sacroiliitis have spondyloarthropathy. Rheumatology (Oxford) 1999, 38:831-836.

77. Chiowchanwisawakit P, Lambert RG, Conner-Spady B, Maksymowych WP: Focal fat lesions at vertebral corners on magnetic resonance imaging predict the development of new syndesmophytes in ankylosing spondylitis. Arthritis Rheum 2011, 63:2215-2225.

78. Dougados M, D'Agostino MA, Benessiano J, Berenbaum F, Breban M, Claudepierre P, Combe B, Dargent-Molina P, Daures JP, Fautrel B, Feydy A, Goupille P, Leblanc V, Logart I, Pham T, Richette P, Roux C, Rudwaleit M, Saraux A, Treluyer JM, van der Hejde D, Wendling D: The DESIR cohort: a 10-year follow-up of early inflammatory back pain in France: study design and baseline characteristics of the 708 recruited patients. Joint Bone Spine 2011, 78:598-603.

79. Hermann J, Giessauf H, Schaffler G, Ofner P, Graninger W: Early spondyloarthritis: usefulness of clinical screening. Rheumatology 2009, 48:812-816.

80. Madsen KB, Schiottz-Christensen B, Jurik AG: Prognostic significance of magnetic resonance imaging changes of the sacroiliac joints in spondyloarthritis: a followup study. J Rheumatol 2010, 37:1718-1727.

81. Maksymowych WP, Crowther SM, Dhillon SS, Conner-Spady B, Lambert RG: Systematic assessment of inflammation by magnetic resonance imaging in the posterior elements of the spine in ankylosing spondylitis. Arthritis Care Res (Hoboken) 2010, 62:4-10.
82. Marzo-Ortega H, McGonagle D, O'Connor P, Hensor EM, Bennett AN, Green MJ, Emery P: Baseline and one year magnetic resonance imaging of the sacroiliac joint and lumbar spine in very early inflammatory back pain: the relationship between symptoms, HLA-B27, and disease extent and persistence. Ann Rheum Dis 2008, 68:1721-7.

83. Oostveen J, Prevo R, den BJ, van de LM: Early detection of sacroiliitis on magnetic resonance imaging and subsequent development of sacroiliitis on plain radiography: a prospective, longitudinal study. J Rheumatol 1999, 26:1953-1958.

84. Pedersen SJ, Chiowchanwisawakit P, Lambert RG, Ostergaard M, Maksymowych WP: Resolution of inflammation following treatment of ankylosing spondylitis is associated with new bone formation. J Rheumatol 2011, 38:1349-1354.

85. Puhakka KB, Jurik AG, Schiottz-Christensen B, Hansen GV, Egund N, Christiansen JV, Stengaard-Pedersen K: MRI abnormalities of sacroiliac joints in early spondylarthropathy: a 1-year follow-up study. Scand J Rheumatol 2004, 33:332-338.

86. Remplik P, Schukai O, Roemer FW, Schalm J, Fischer W, Bucklein W, Mott K, Bohndorf $K$ : [Influence of clinical information on the diagnostic validity of MRI in the detection of abacterial sacroiliitis]. Rofo 2005, 177:842-848.

87. Shankar S, Abhisheka K, Kumar AVSA, Chaturvedi A: Evaluation of magnetic resonance imaging and radionuclide bone scan in early spondyloarthropathy. Indian J Rheumatol 2009, 4:142-148.

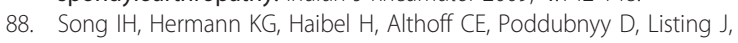
Weiss A, Freundlich B, Rudwaleit M, Sieper J: Relationship between active inflammatory lesions in the spine and sacroiliac joints and new development of chronic lesions on whole-body MRI in early axial spondyloarthritis: results of the ESTHER trial at week 48. Ann Rheum Dis 2011, 70:1257-1263.

doi:10.1186/ar3768

Cite this article as: Arnbak et al:: A systematic critical review on MRI in spondyloarthritis. Arthritis Research \& Therapy 2012 14:R55.

\section{Submit your next manuscript to BioMed Central and take full advantage of:}

- Convenient online submission

- Thorough peer review

- No space constraints or color figure charges

- Immediate publication on acceptance

- Inclusion in PubMed, CAS, Scopus and Google Scholar

- Research which is freely available for redistribution

Submit your manuscript at www.biomedcentral.com/submit
Ciomed Central 